\title{
Electric kick bike design for a recreational vehicle
}

\author{
T.S. Pambudi, A.W. Heru, A. Deefinpramasya \& V.R. Ramdhan \\ Telkom University, Bandung, Indonesia
}

\begin{abstract}
Amusement parks are a popular tourist destinations. Usually, in the amusement park there is a relaxing area, a natural landscape, as well as a playground with various entertainment attractions. There are several modes of transportation available to accommodate user access to all areas or just admiring the beautiful scenery. One alternative is the kick bike with additional electric power to make it easier for users and not get tired when driving around in an amusement park, especially the uphill area. An electric kick bike was chosen as an alternative to attract young adult visitors to visit the amusement park. The research to be conducted is qualitative. Qualitative research is a method for exploring and understanding the activities and needs of amusement park visitors. Based on this potential, this research will design an electric kick bike for a recreational vehicle. The aim of this research is how to create an environmentally friendly vehicle as transportation as well as a recreational vehicle for amusement park visitors
\end{abstract}

Keywords: vehicle, kick bike, design, environmentally friendly

\section{INTRODUCTION}

The amusement park is a trendy tourist place, which not only offers beautiful natural attractions but also provides a variety of attractions for family games available in the amusement park area. The amusement park provides transportation facilities, both mass transportation and personal transportation, as well as recreational vehicles. One alternative for individual vehicles, as well as amusement park attractions, is the kick bike. The kick bike itself is a kind of scooter vehicle with a larger dimension on the wheels and frame compared with a conventional scooter. This vehicle (is) also an answer to accommodate the needs of attraction vehicles for young adults. Besides, this kick bike will be equipped with an additional electric engine to add power to facilitate users when going through the uphill terrain in the amusement park area.

The choice of kick bike with the addition of electric power is to create environmentally friendly transportation. By using an electric motor that does not produce carbon residues will help reduce environmental pollution. Based on the previous explanation, this research will design a kick bike with the addition of electric power. The goal is to provide modes of transportation and attractions for amusement park visitors that are environmentally friendly, based on the activities and needs of young adult visitors.

\subsection{Sustainable design}

In the early 1990s, the concepts of eco-design and green product design had emerged, which were a company's strategy to reduce the negative impact on the environment from the results of their industrial production activities. Until 1997, UNEP announced a statement on eco-design: "the concept of eco-design was an agreement to create sustainable products and consumption" (UNEP 2009).

This statement is the beginning of today's concept of sustainable design. As the issue of global environmental damage is increasingly visible, this forces the global industrial community to focus 
more on the environmental impacts of their production waste. This motivates companies to be more innovative in the activities of the production process and create better products, so as to balance the development of industrial speed with the environment. Also, environmental groups have broadened their scope by including social, economic, and environmental issues in the concept of sustainable design.

\subsection{Kick bike}

Kick bikes are human-powered road vehicles with handlebars, a deck, and wheels driven by being pushed using feet on the ground. Material that are used to make these vehicles are aluminum and steel. The significant difference between conventional scooters is the dimensions of the frame and wheels. On kick bikes, the frame dimensions are more extensive, with sizes based on the standard geometry of the bike. The large frame size is because the targeted kick bike users are adults. Also, the size of the wheels on the kick bike is more significant than the wheels on the scooter. The goal is with large wheels, creating a more massive wheel rotation and making it easier for kick bikes to pass various terrain or road types. A kick bike that will be designed is a combination of the form of a bicycle and a scooter. Where this vehicle has large bicycle tires that are driven by being pushed with legs like a scooter, this kick bike has dimensions according to the ergonomics of adults.

\subsection{Electric motor}

The electric motor is a tool to convert electrical energy into mechanical energy. Tools that function in reverse, converting mechanical energy into electrical energy, are called generators or dynamos. Electric motors are in every household appliance such as fans, washing machines, water pumps, and vacuum cleaners.

Today, the typical electric motor used for a modern electric bike is (a) BLDC or Brushless DC motor drive. BLDC moto(r) drive is commonly used because it is easy to apply to the bike and also more efficient (Ohio Electric Motors 2012). There are two models of BLDC motor drive: the first BLDC mid-drive and the second, more popular one, are BLDC hub drives. BLDC hub drives are made by putting the electricity into the wheel hub itself, while the stator is fixed solidly to the axle. The bicycle wheel hub is the motor; the result is more powerful (and) more efficient.

\subsection{Bike geometry}

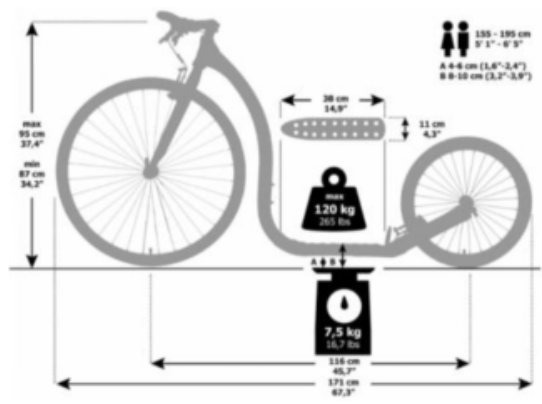

Figure 1. Geometry Info Race Max 20. (source: www.kickbike.com)

Vehicle geometry is the dimension of the vehicle and the driver's position based on the concept of ergonomics. The geometry is fundamental because it affects the comfort, safety, and handling of the vehicle. The following is the kick bike geometry that will be the basis of the design; the geometry refers to products from the kick bike (Kickbike.com) 


\section{METHOD}

The research to be conducted is qualitative. Qualitative research is the method for exploring and understanding the meaning of individuals or groups of people ascribed to social or humanitarian problems. This process requires essential efforts, such as asking questions to collect specific data from participants, analyzing data inductively, and interpreting the meaning of the data obtained. The results of this study are usually flexible (Creswell 2010).

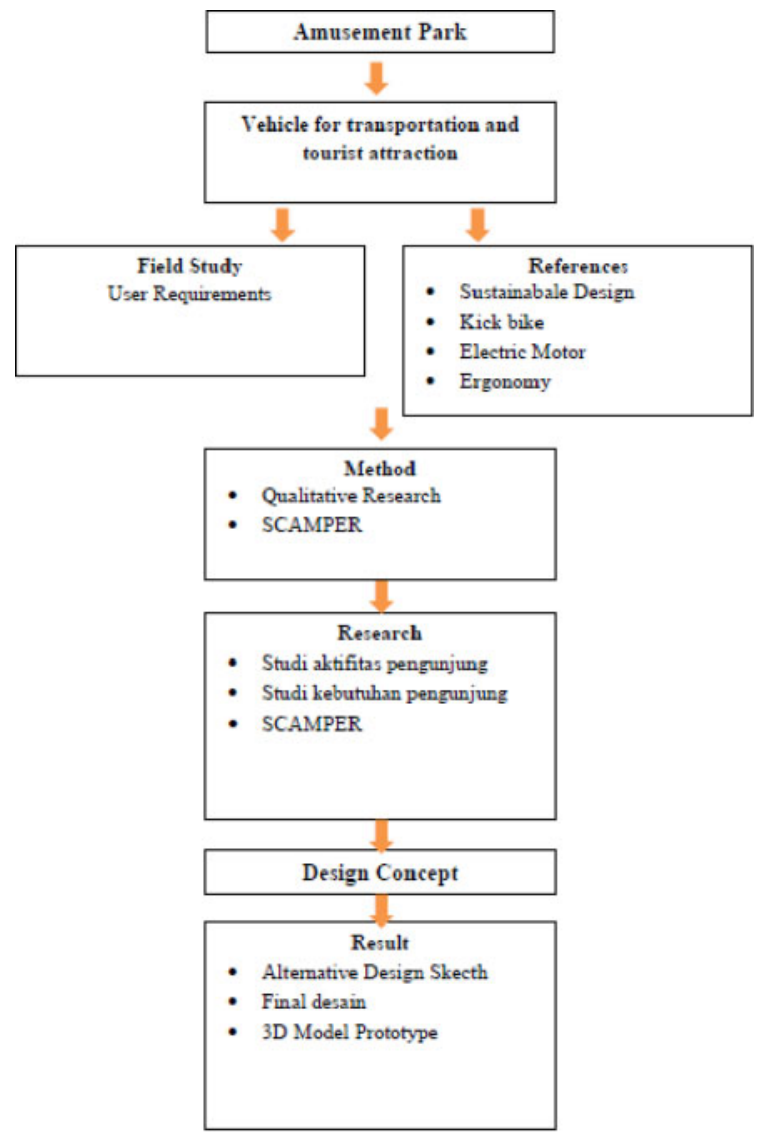

Figure 2. Research flowchart.

The qualitative research strategy applied in this design is a study approach to the activities and needs of users for the basis of product design. The design process then uses the SCAMPER technique based on similar products on the market.

SCAMPER stands for Substitute, Combine, Adapt, Modify, Put to another use, Eliminate, and Reverse. Therefore, this technique is a collection of creative problem-solving methods based on design thinking methods. In use, we can choose one or several existing methods to use. The following ways will carry the data collection process:

1. observe the activities and needs of amusement park visitors,

2. study of literature on sustainable design and vehicles that has a sustainable design concept, and

3. study existing products in the market to guiding for (guide) the design process using the SCAMPER technique. 


\subsection{User requirements study}

The process of obtaining data was carried out by interviewing several park visitors whose ages ranged from 14-26 years. In the interview conducted, an alternative kick bike as a vehicle is offered based on what visitors desire. From the results of the interviews conducted there are several important points, one of which is the ease of use. According to most visitors, they want a vehicle that is easy to use for various things while driving around the park, e.g., safety of goods carried by visitors, when visitors use vehicles, and carrying luggage safely without having to store it.

The conclusion from the study of end requirements is that vehicles needed by park visitors are vehicles that make are (that are) easy for visitors to use or at least not difficult, as well as having a place to carry goods in the vehicle.

\subsection{Design aspect: SCAMPER}

The first SCAMPER method used for finding the design aspect is Substitute. Replace the wheels on conventional scooters with bicycle wheels (16" in diameter), because the size of the wheels on a conventional scooter are too small. With a larger wheel diameter, the bike will be able to be easily pushed using the feet lightly and be able to cross the terrain with different contours.

The second is Combine - combine human power with an electric motor on a kick bike. The use of an electric motor is to help move the kick bike when used for transportation around an amusement park. It is also to help tourists when passing the uphill area. The choice of an electric motor is also one of implementation on (of) the concept of sustainable design, which is one of the recommendations for environmentally friendly vehicles is to use electric motor power. Electric motors produce no waste and have a lower carbon footprint. Electric motors also have a more compact size and are easier to install in vehicles.

The third SCAMPER method that we used is Adapt. For reasons of driver safety, it is necessary to have adequate brakes to support safety when driving the kick bike. When using the vehicle in areas with varying contours, and crowded by people passing by, it needs a brake that reliably controls the speed. Based on these needs, the kick bike adopts the braking system of the bicycle, the dual-pivot calliper brake type. This type of brake is commonly used for braking systems on daily use bicycles in urban areas. Also, the dual-pivot calliper brake is easy to install and maintain. Adding a basket to the back of the kick bike accommodates the need to carry bags or goods when using the vehicle. With this additional back basket, the tourist who uses this vehicle will be able to carry their bags safely.

\section{RESULT}

\subsection{Concept design}

The electric kick bike design aims to be a mode of transportation and attraction in amusement parks. Kick bikes are designed for adults based on ergonomy and bike geometry. This vehicle also uses a large wheel diameter so that it is easier to use in various types of areas. It has the addition of an electric motor for driving power to help the driver when traveling uphill. In this vehicle, there is also a luggage basket located at the back of the kick bike. Due to its simple and functional design, the kick bike is expected to attract riders, both for transportation around the park as well as a vehicle for visitor attractions.

\subsection{Term of reference}

1. Design Considerations: The design must meet the needs of the amusement park. First, the vehicle must attract the interest of visitors. Second, there is a container to carry luggage on the vehicle so that luggage remains safe when driving. Third, the addition of an electric motor helps the vehicle when traveling uphill. Finally, it (is) is more environmentally friendly and energy efficient.

2. Design Limits: The construction and material used must be sturdy to withstand shocks when used in areas with rough terrain. The BLDC type of electric motor comes with a rechargeable battery 
so usage time is limited. The dimensions of the kick bike are based only on adult geometry. Kick bikes are specifically designed for use in amusement parks.

3. Design Description: The product designed is a kick bike using an electric motor as additional power. It is for transportation around an amusement park. This vehicle is also equipped with a basket as a place for visitors' luggage when driving. The kick bike target users are teenagers and adults.

\subsection{Product visualization (visualization)}
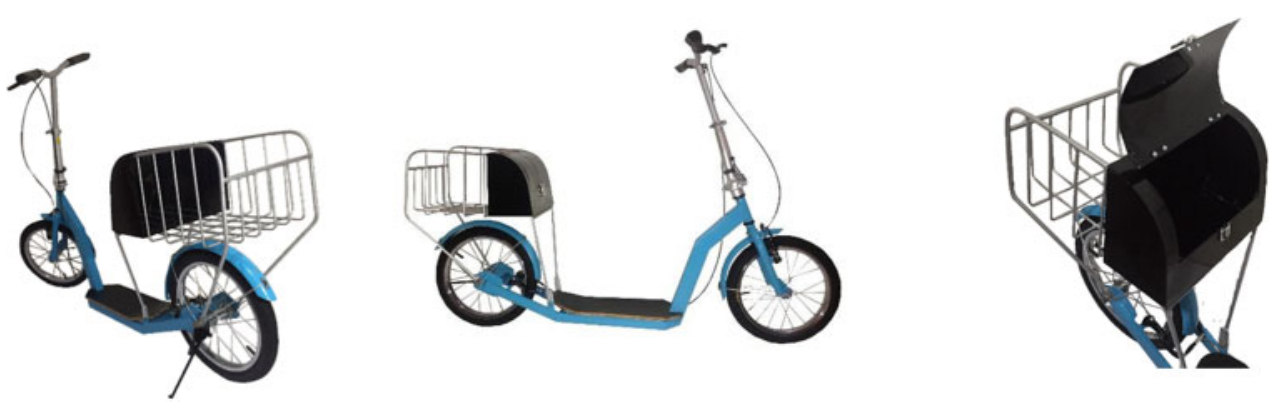

Figure 3. A 3D model rendering of an electric kick bike.

\section{CONCLUSION}

The conclusion of this research is that the electric kick bike is one of the solutions that we choose to accommodate the need for transportation and attraction in an amusement park. The electric motor drive chosen to be added on the kick bike provides more power that can help tourists efficiently drive the vehicle uphill. An additional feature that adds function to the kick bike is the rear basket for carrying luggage safely. Furthermore, the electric kick bike will become one of the choice ways for young-adult tourists to enjoy the amusement park. The next step is to figure out how to apply the design concept and product visualization to the scaled model and so that it can become a product prototype.

\section{REFERENCES}

Creswell, John W. 2010. Research Design: Pendekatan Kualitatif, Kuantitatif, dan Mixed. (diterjemahkan oleh: Achmad Fawaid). Yogyakarta: Pustaka Pelajar.

Eberle, Bob. 1996. Scamper: Games for Imagination Development. Prufrock Press Inc.

KickBike. 2018. Geometry Info Race Max 20. https://kickbike.com/showroom_en/product-race-max-20.html McLennan, J. F. 2004. The Philosophy of Sustainable Design: The Future of Architecture. Kansas City: Ecotone LLC.

Ohio Electric Motors. 2012. Brushless DC Motors Used in Industrial Applications. http://www.ohio electricmotors.com.

Swifty Scooters. 2020. SwiftyOne MK3. www.swiftyscooters.com

UNEP. 2009. UNEP Year Book 2009: New Science and Developments in Our Changing Environment. United Nations Environment Programme, Kenya

Walker, Stuart. 2006. Sustainable by Design: Explorations in Theory and Practice. Earthscan: London. 